\title{
Earlier palliative home care is associated with patient-centred medical resource utilisation and lower costs in the last 30 days before death in COPD: a population-level decedent cohort study
}

\author{
Charlotte Scheerens ${ }^{1,2,3}$, Kristof Faes ${ }^{1,2,3}$, Peter Pype ${ }^{1,2,3}$, Kim Beernaert ${ }^{1,2,3}$, \\ Guy Joos (i) $^{4,5}$, Eric Derom ${ }^{4,5}$, Joachim Cohen ${ }^{1,2,6}$, Luc Deliens ${ }^{1,2,3,6,7}$ and \\ Kenneth Chambaere ${ }^{1,2,3,7}$
}

Affiliations: ${ }^{1}$ End-of-Life Care Research Group, Ghent University, Ghent, Belgium. ${ }^{2}$ End-of-Life Care Research Group, Vrije Universiteit Brussel (VUB), Brussels, Belgium. ${ }^{3}$ Dept of Public Health and Primary Care, Ghent University, Ghent, Belgium. ${ }^{4}$ Dept of Respiratory Medicine, Ghent University Hospital, Ghent, Belgium. ${ }^{5}$ Dept of Internal Medicine and Pediatrics, Ghent University, Ghent, Belgium. ${ }^{6}$ Dept of Family Medicine and Chronic Care, Vrije Universiteit Brussel (VUB), Brussels, Belgium. ${ }^{7}$ Contributed equally as last author.

Correspondence: Charlotte Scheerens, Universiteit Gent, End-of-life Care Research Group, De Pintelaan 185, 9000 Ghent, Belgium. E-mail: charlotte.scheerensquugent.be

@ERSpublications

Palliative home care is associated with more patient-centred care and reduced costs in the final month of life for people with COPD http://bit.ly/2Pr2U1i

Cite this article as: Scheerens C, Faes K, Pype P, et al. Earlier palliative home care is associated with patient-centred medical resource utilisation and lower costs in the last 30 days before death in COPD: a population-level decedent cohort study. Eur Respir J 2020; 55: 1901139 [https://doi.org/10.1183/ 13993003.01139-2019].

ABSTRACT COPD patients often use many medical resources, such as hospital admissions and medical imaging, inappropriately close to death. Palliative home care (PHC) could beneficially affect this. The aim was to study the effect of use and timing of PHC on medical resource use and costs in the last 30 days before death (DBD) for COPD.

We performed a retrospective study of all Belgian decedents in 2010-2015 with COPD and a primary cause of death being COPD or cardiovascular diseases. Odds ratios for medical resources were calculated between using and four PHC timing categories (>360, 360-181, 180-91 and 90-31 DBD) versus not using. Confounders were socio-demographic, care intensity and disease severity variables.

Of the 58527 decedents with COPD, 644 (1.1\%) patients received PHC earlier than $30 \mathrm{DBD}$. Using PHC (versus not using) decreased the odds ratio for hospitalisation (0.35), intensive care unit admission (0.16), specialist contacts (0.58), invasive ventilation (0.13), medical imaging including chest radiograph (0.34), sedatives (0.48) and hospital death (0.14). It increased the odds ratio for home care (3.27), general practitioner contact (4.65), palliative care unit admission (2.61), noninvasive ventilation (2.65), gastric tube (2.15), oxygen (2.22) and opioids (4.04) $(\mathrm{p}<0.001)$. Mean total healthcare costs were $€ 1569$ lower for using PHC. All PHC timing categories showed a benefit in medical resource use and costs. However, we observed the largest benefit in the category PHC 90-31 DBD.

Health policy and services should focus on increasing PHC access, while research should further explore early PHC initiation for COPD. 


\section{Introduction}

COPD is one of the leading causes of death, with global prevalence estimated to further rise in the near future [1]. There are a number of studies signalising medical resource use that might be inappropriate close to death for COPD, such as diagnostic testing, frequent acute hospitalisations in the last 30 days before death [2] and life-prolonging care instead of comfort care in the last week before an expected death [3]. Earlier research has shown that end-stage COPD patients prefer to be cared for at home [4] and suffer from symptoms such as low mood, breathlessness, sleeping problems, anxiety [5]. These symptoms reflect their palliative care needs [5], which can be supported by palliative home care (PHC) if the patient's situation allows it.

The World Health Organization [6] advocates a timely initiation of PHC. This type of support might better align medical resource use with patient care preferences, as the patient-centred approach takes into account individual care needs and wishes in a timely manner [7]. A 2016 US-based study exploring the effects of PHC on healthcare use for COPD patients reported less hospital use and lower costs [8]. Other studies showed that PHC reduces hospital death $[9,10]$, improves patients' quality of life [11-13] and decreases symptom burden [14]. However, despite these promising study results and pleas from health organisations, only a small minority of COPD patients receive PHC $[3,5,15]$, and, if so, predominantly very close to death [2].

A number of studies have reported on the link between palliative care and lower medical resource use for COPD such as hospitalisations $[8,16]$. However, population-level evidence is lacking, although it could give us more insight into the provision of appropriate end-of-life care in COPD. Here, we report population-wide retrospective study results describing the effect of use and timing of PHC, provided by multidisciplinary teams in Belgium (see table 1 for explanation of PHC and comparison with hospice care), on medical resource use and costs in COPD. Two research questions are addressed: 1) How do medical resource use and costs in the last 30 days before death differ between COPD patients using PHC versus those who did not? 2) How do medical resource use and costs in the last 30 days before death differ between COPD patients using PHC for the first time $>360,360-181,180-91$ and 90-31 days before death versus those who did not?

\section{Methods}

\section{Study design and setting}

Following strobe-guidelines (see checklist in Appendix 4), we performed a retrospective full population analysis of people dying with COPD between January 1, 2010, and December 31, 2015, in Belgium.

\section{Data sources}

A total of seven administrative and health claims databases were linked to create one common full population database [18]. Data consisted of health claims data retrieved from the InterMutualistic Agency (IMA) and socio-demographic, socioeconomic and death certificate data from Statistics Belgium. In short, the IMA

\section{TABLE 1 Palliative home care (PHC) teams in Belgium}

\section{Organisation}

Belgium has region-bound $\mathrm{PHC}$, which is a separate secondary care service. $\mathrm{PHC}$ is somewhat similar to hospice care teams in the USA, although the latter takes over care whereas PHC teams in Belgium support the regular care services in providing palliative care. They are a multidisciplinary team consisting of a PHC physician, PHC nurses and a psychologist. In total, 27 networks lof which, 15 are in Flanders) are operating in Belgium. The patient's general practitioner (GP), depending on the patient's individual context, requests PHC. This is mostly in consultation with the patient, informal carers, involved community nurses, palliative care nurses in the hospital or specialists. The main focus of PHC teams are home visits by the PHC nurses to support the patient and informal carers for psychological, social, physical and spiritual needs (holistic approach). PHC nurses also collaborate with the involved GP if necessary. The PHC physician and the PHC psychologist are involved in weekly meetings and in psychological support for patients and informal carers. Although variation exists, most PHC teams do not use standardised documents or scales to assess the symptoms and needs of the patients. Rather, they report in a general electronic patient file, which they do not systematically share with other health professionals. Contact with the latter is mainly by telephone.

\section{Palliative status}

Before referring patients to PHC, the responsible GP can request an optional "palliative status" which is a formal statute, unique to Belgium, tied to healthcare reimbursement of costs related to the palliative phase. The reimbursement system for PHC in Flanders is by law restricted to patients with 3 months life expectancy, with the possibility of making a second claim [17]. This changed to 6 months in November 2018. If a GP does not request a palliative status, patients can still receive PHC. The capitated hospice benefit in the USA is a similar statute allowing for reimbursement of medical (home) care costs towards the end of life if the patient meets specific criteria, such as a 6-month life expectancy. 
database contains all reimbursed healthcare consumption and pharmaceutical dispensing data for all Belgian citizens [19]. Statistics Belgium manages the national demographic database, derived from the population registry [20] and Census 2011 data [21]. Finally, we linked a fiscal database (i.e. net taxable household income), also managed by Statistics Belgium, to allow additional socio-economic insights. A common unique identifier (i.e. social security number) made deterministic linking possible. A detailed description of the databases, the data linkage process, quality and content are described in detail elsewhere [18].

\section{Study population}

For the study population, we first selected all those who died with COPD. Then we extracted two groups from that selection based on their underlying cause of death noted on the death certificate in Belgium between 2010 and 2015: 1) those who died of COPD (International Classification of Diseases, 10th Revision, ICD10-codes: J41-44) and 2) those who died of cardiovascular diseases (ICD10-code I00-I99). We only included these primary causes of death because previous population-based research in Belgium found similar referral to PHC for both [22]. Cardiovascular diseases are also the second most common cause of death and comorbidity in COPD, after COPD itself [23]. We excluded those dying with COPD and of lung cancer, because of the strong association between PHC and cancer which could cause biased results [3].

\section{Variables and measures \\ Outcomes: medical resource use in the last 30 days before death}

First, medical healthcare resources were selected using insights from similar studies [2, 22, 24]. A multidisciplinary group of researchers (a pulmonologist, sociologists and general practitioners) decided upon the final selection which can be clustered in four groups. 1) Hospital and primary care interventions and admissions: hospitalisation, emergency room, intensive care unit, palliative care unit, one-day care, home care and contacts with general practitioner (GP), specialist and physiotherapist. 2) Medical procedures typical for COPD patients and end-of-life care: invasive ventilation, non-invasive ventilation, urinary tract catheter, cardiopulmonary resuscitation, medical imaging, chest radiograph and spirometry. 3) Medication for COPD and comfort: oxygen, COPD medication, opioids, sedatives, morphine. 4) Place of death: in hospital, at home or in a nursing home.

The IMA healthcare and pharmaceutical databases coded healthcare activities and medication data respectively as nomenclature codes for reimbursement purposes and Anatomical Therapeutic Classification (ATC) codes. In order to answer our research questions, we interpreted and aggregated specific nomenclature numbers into meaningful care interventions/admissions, procedures, medication and place of death categories.

\section{Outcomes: medical costs in the last 30 days before death}

Based on all specific healthcare consumption data, we calculated total healthcare costs from a third party and patient co-payment perspective, consisting of total inpatient cost and total outpatient cost for both groups. Inpatient costs included all specific intervention and medication costs in the hospital. Outpatient costs included all specific intervention and medication costs outside the hospital. For a detailed description, please refer to the supplementary material. Based on the exact dates of delivery, we calculated the total inpatient and outpatient costs for the last 30 days before death by specific timing category of receiving PHC. We actualised all costs to 2017 values based on the unit cost of all defined resources in that year.

\section{Exposure: PHC use and timing}

We defined the exposure, using PHC, as receiving a minimum of one home visit from a multidisciplinary PHC team in the last two years before death. We operationalised this with a categorical variable of timing in days before death, which we defined for analysis purposes based upon the dates related to a code for the first reimbursement of costs related to PHC. This did not give us insights in the frequency of PHC visits, as we could not derive this from the data.

To compare medical resource use and costs between those who did receive PHC at least once in the two years before death and those who did not, the selected data had to meet two conditions. Firstly, the exposure variable (PHC) had to occur before the outcome variable (medical resource use in the last 30 days before death) to meet the criterion of temporality of our design. Therefore, we selected only those who used PHC at least one month before death, while analysing medical resource use and costs in the last 30 days before death. For the outcome place of death, however, we could also include those who used PHC in the last month of life, as this posed no problem for the temporality criterion. 
Second, we minimised confounding factors by controlling for as many covariates as possible that could potentially affect the results. We identified relevant and measurable covariates from a comprehensive set of clinically significant possible risk factors used in similar research [2, 24, 25]: 1) socio-economic covariates: age, sex, household type, educational level attained, taxable income, Charlson comorbidity index, year of death, urbanisation level of the municipality of residence; 2) medical resource use related to care intensity and disease severity covariates between two years and 30 days before death: number of home care visits from a community nurse with a palliative character in the last 360 days before death (this is not the same as PHC visits), mean length of stay after admission to an intensive care unit, number of hospital, one-day care and emergency room admissions, number of chest radiographs and invasive ventilations and number of contacts with a GP, physiotherapist and specialist. We excluded confounders if there was a conceptual overlap with the particular outcome variable to avoid multicollinearity (Appendix 1).

Besides describing the effect of PHC use on specific resource use and costs, we also analysed the timing of first PHC use. For this, we distinguished four timing categories: 1) having received PHC for the first time $>360$, 2) between 360 and 181, 3) between 180 and 91 and 4) between 90 and 31 days before death. This distinction was based on 1) the eligibility criteria for reimbursement of PHC-related costs in Belgium as determined by law in 2010-2015, which stated a maximum life expectancy of 90 days; 2) for analysis purposes: to calculate odds ratios of medical resource use between each timing category and those who did not use PHC.

Finally, participant characteristics included sex, age at death, urbanisation level of the municipality of residence, educational level attained, household type, Charlson comorbidity index and taxable income.

\section{Statistical analysis}

We conducted multivariable analysis controlling for many covariates, using SAS version 9.3. The aim here was to approximate the advantages of randomisation and the prospective setting of a trial, as the latter would be impossible to execute for ethical and practical reasons. To investigate potential differences, we compared patient characteristics, resource use and costs for PHC use versus not using, by performing chi-squared tests for categorical variables and Wilcoxon rank sum tests for continuous variables. Resource data were then analysed using logistic regression (odds ratios) for all variables, with using PHC versus not using PHC (reference category) as independent variables and controlling simultaneously for various covariates (see subsection on measures). We set the significance level at $p \leqslant 0.05$. We analysed timing of PHC by offsetting each timing category against no PHC.

In accordance with Belgian law, approvals for access to the various databases and the database integrating all databases were obtained from two separate national sectoral committees for privacy protection: the Sectoral Committee of Social Security and Health, Section Health and the Statistical Supervisory Committee. Both are subcommittees of the Belgian Commission for the Protection of Privacy. Additionally, the ethics committee of the Ghent University Hospital granted its approval (B670201422382).

\section{Results}

Between 2010 and 2015, 642901 people died in Belgium. Of those, 634445 (98.7\%) were insured by one of the eight health insurance funds and therefore had data on reimbursement of healthcare and medication data.

\section{Population characteristics}

Of all 634445 insured people who died in 2010-2015, 58527 (9.1\%) died with COPD and died of COPD or of cardiovascular diseases. Of those 58527, 1751 (3.0\%) used PHC, of which 644 earlier than the last 30 days before death (figure 1). The majority of these 644 were men (59.8\%), 75-84 (38.5\%) years old, received primary education only (30.3\%), lived with their partner $(49.2 \%)$ and died of COPD (57.6\% versus $41.4 \%$ for not using PHC; $\mathrm{p}<0.001)$. Both groups had equal numbers of comorbidities, urbanisation and income levels (tables 2 and 3). Appendix 1 shows the population characteristics for the PHC timing categories.

\section{Medical resource use}

The bivariate results of medical resource use (table 4) show that for care interventions and admissions, those who used PHC versus those who did not were hospitalised less often (24.7\% versus $47.9 \%)$ and for shorter periods (2.6 versus 5.3 days). They were less often admitted to the intensive care unit (3.7\% versus $19.2 \%)$, one-day care ( $0.9 \%$ versus $2.1 \%)$, and seen by specialists $(9.2 \%$ versus $16.9 \%)$. They used more often palliative care unit care $(7.6 \%$ versus $1.4 \%)$, home care $(73.1 \%$ versus $32.2 \%)$, physiotherapist contact (55.6\% versus $50.5 \%)$ and GP contact (91.1\% versus $75.4 \%$ ) of which the latter happened more frequently 


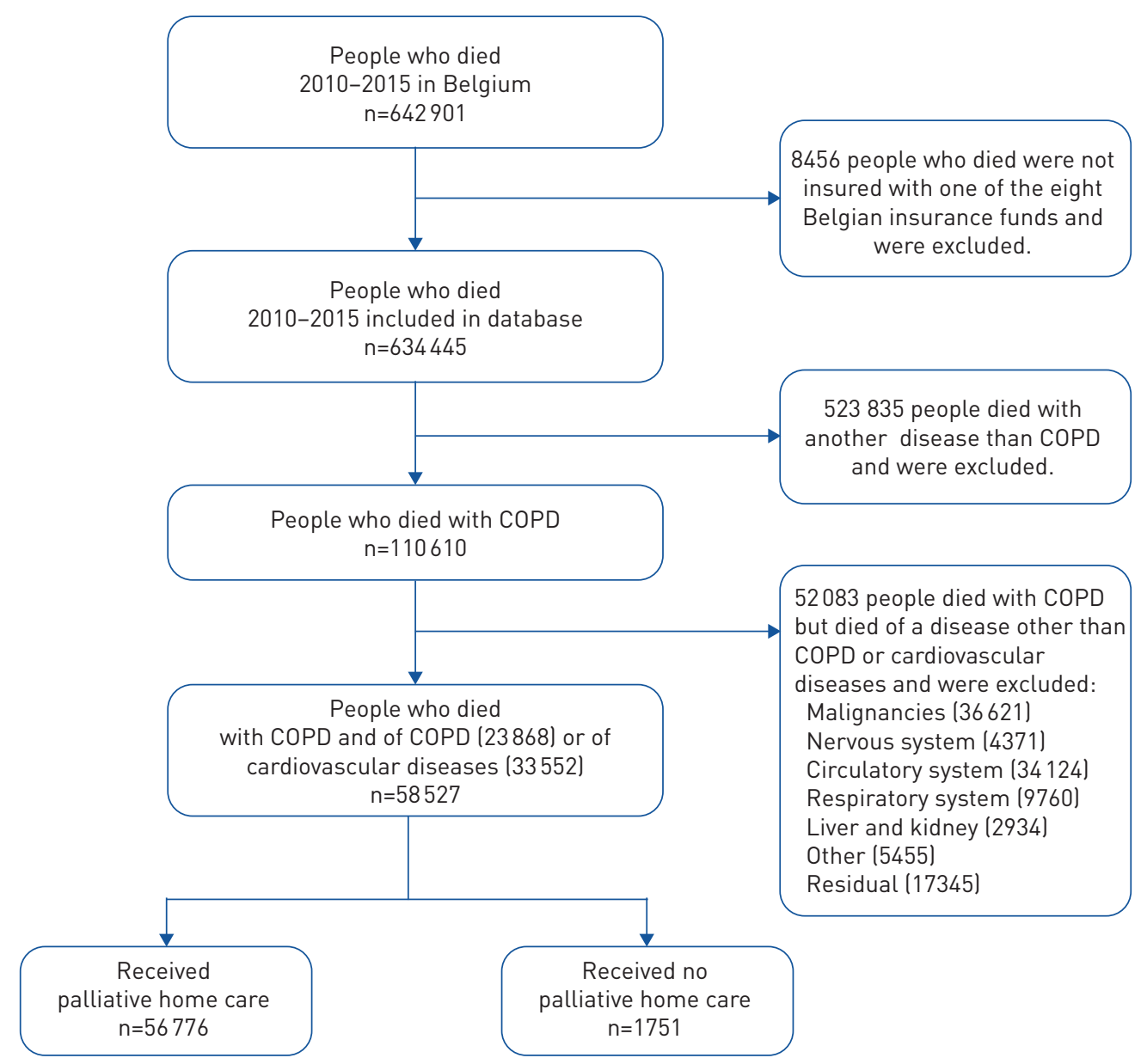

FIGURE 1 Flow chart of patients in the study.

(5.7 versus 2.4) $(\mathrm{p}<0.001)$. Concerning procedures, they received less often invasive ventilation $(1.2 \%$ versus $8.6 \%)$, cardiopulmonary resuscitation $(0.3 \%$ versus $2.0 \%)$ and medical imaging including chest radiographs (27.0\% versus $60.0 \%)$, but more often noninvasive ventilation $(61.2 \%$ versus $24.0 \%)(\mathrm{p}<0.001)$. On medication, PHC users were administered sedatives less often (12.6\% versus $20.0 \%$ ), but more often oxygen $(14.0 \%$ versus $6.0 \%)$, opioids $(66.8 \%$ versus $33.1 \%)$ and morphine $(43.3 \%$ versus $13.2 \%)(\mathrm{p}<0.001)$. Finally, they less often died in the hospital (15.6\% versus $55.0 \%)$, but more often at home (60.8\% versus $25.9 \%)$ or in a nursing home $(23.6 \%$ versus $19.1 \%)(\mathrm{p}<0.001)$.

Multivariable tests (table 4) controlling simultaneously for the identified confounders (Appendix 1) confirmed these results, except for one-day care (not enough cases) and physiotherapist contact (not significant). Differences for length of stay at the intensive care unit, number of specialist and physiotherapist contact, gastric tube, urinary tract catheter, spirometry and COPD drugs were very small or not existent.

Furthermore, odds for medical resource use between the four PHC timing categories versus no PHC revealed that using PHC 90-31 days before death showed the largest increase for home care, non-invasive ventilation, opioids and morphine $(\mathrm{p}<0.001)$ (figure $2 \mathrm{a}$ ) and the largest decrease in all resource use variables from figure $2 \mathrm{a}$ except for nursing home deaths $(\mathrm{p}<0.001)$. Appendix 3 shows detailed bivariate and multivariate results.

\section{Healthcare costs}

Descriptive healthcare cost results show that mean total inpatient costs were lower for people using PHC $(€ 2492$, 95\% CI $€ 2142-2841)$ than for those who did not (€5583, 95\% CI $€ 5526-5641)$. Mean total outpatient costs were higher for PHC use ( $€ 2542$, 95\% CI $€ 2422-2661$ versus $€ 1020,95 \%$ CI $€ 1010-1029)$ and mean total healthcare costs were $€ 1569$ lower ( $€ 5034,95 \%$ CI $€ 4703-5364$ versus $€ 6603$, 95\% CI €6546-6659). Results per PHC timing category versus no PHC were similar, but using PHC 90-31 days before death showed the largest differences (table 5). 


\begin{tabular}{|c|c|c|c|}
\hline Demographics & $\begin{array}{l}\text { No palliative } \\
\text { home care }\end{array}$ & $\begin{array}{l}\text { Palliative home } \\
\text { care }>30 \text { DBD }^{f}\end{array}$ & p-value \\
\hline Selected group ${ }^{\#}$ & $56776(97.0)$ & $644(1.1)$ & \\
\hline Sex & & & 0.5483 \\
\hline Male & 33965 (59.8) & 385 (59.8) & \\
\hline Female & 22811 (40.2) & $259(40.2)$ & \\
\hline Age years ${ }^{\natural}$ & & & 0.0007 \\
\hline $18-64$ & 5548 (9.8) & $75(11.6)$ & \\
\hline $65-74$ & $9897(17.4)$ & $127(19.7)$ & \\
\hline $75-84$ & 20963 (36.9) & $248(38.5)$ & \\
\hline $85-94$ & $18581(32.7)$ & 179 (27.8) & \\
\hline$\geqslant 95$ & $1744(3.1)$ & $14(2.2)$ & \\
\hline Educational level ${ }^{\Uparrow,+}$ & & & $<0.0001$ \\
\hline None & $4276(7.5)$ & $54(8.4)$ & \\
\hline Primary & $17295(30.5)$ & 195 (30.3) & \\
\hline Lower secondary & $10430(18.4)$ & $144(22.4)$ & \\
\hline Upper secondary & 5925 (10.4) & 79 (12.3) & \\
\hline Higher & $2988(5.3)$ & $48(7.5)$ & \\
\hline Household type Il $^{1}$ & & & $<0.0001$ \\
\hline Single person & $17939(31.6)$ & $161(25.0)$ & \\
\hline Living together, with no children in household & $21207(37.4)$ & $317(49.2)$ & \\
\hline Living together, with children in household & $4086(7.2)$ & $50(7.8)$ & \\
\hline One-parent family & $2874(5.1)$ & $45(7.0)$ & \\
\hline Other household types & $1320(2.3)$ & $13(2.0)$ & \\
\hline Collective (nursing home, psychiatric hospital) & $9299(16.4)$ & $58(9.0)$ & \\
\hline Urbanisation? & & & 0.0018 \\
\hline Very high & 17157 (30.2) & $196(30.4)$ & \\
\hline High & $15818(27.9)$ & $185(28.7)$ & \\
\hline Average & 15508 (27.3) & $158(24.5)$ & \\
\hline Low & $7015(12.4)$ & $93(14.4)$ & \\
\hline Rural & $833(1.5)$ & $9(1.4)$ & \\
\hline Cause of death" & & & $<0.0001$ \\
\hline COPD & $23497(41.4)$ & $371(57.6)$ & \\
\hline Cardiovascular disease & $33279(58.6)$ & $273(42.4)$ & \\
\hline \multicolumn{4}{|l|}{ Previous hospitalisations ${ }^{\natural}$} \\
\hline Mean LOS hospitalisations in the past 2 years until 30 DBD & $38.1(38.2-39.1)$ & $51.6(45.5-58.3)$ & $<0.0001$ \\
\hline Hospitalisations in the past 2 years until 30 DBD & $2.6 \pm 2.7$ & $4.2 \pm 3.6$ & $<0.0001$ \\
\hline Charlson Comorbidity Index & & & 0.0217 \\
\hline 0 & $48790(85.9)$ & $559(86.8)$ & \\
\hline 1 & $6847(12.1)$ & $52(8.1)$ & \\
\hline 2 & $2083(3.7)$ & $26(4.0)$ & \\
\hline$\geqslant 3$ & $353(0.6)$ & $7(1.1)$ & \\
\hline 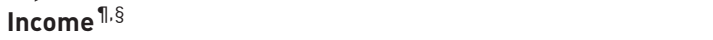 & & & 0.9618 \\
\hline Lowest 40\% & $6107(10.8)$ & $78(12.1)$ & \\
\hline $41-60 \%$ & $31916(56.2)$ & $367(57.0)$ & \\
\hline \multicolumn{4}{|l|}{ Region $\rrbracket$} \\
\hline Brussels capital region & $33021(58.2)$ & $361(56.1)$ & $<0.0001$ \\
\hline Flanders & $19372(34.1)$ & $236(36.6)$ & \\
\hline Wallonia & $3938(6.9)$ & $44(6.8)$ & \\
\hline Unknown & $445(0.78)$ & $3(0.5)$ & \\
\hline
\end{tabular}

Data are presented as $\mathrm{n}(\%)$, mean (range) or mean $\pm \mathrm{SD}$, unless otherwise stated. DBD: days before death; LOS: length of stay. ${ }^{\#}$ : percentage of total population included in the database ( $\left.n=58527\right)$; ": column percentages; ${ }^{+}: 28.0 \%$ missing values for no palliative home care and $21.0 \%$ for palliative home care; ${ }^{\S}$ : income percentages represent the proportion of the total population's income; ${ }^{f}$ : 644 patients received palliative home care earlier than 30 days before death.

\section{Discussion}

\section{Summary of the results}

This population-level study using administrative data of 58527 COPD who died between 2010 and 2015 shows that receiving PHC changes medical resource use in the last 30 days before death for people with COPD. Those using PHC (versus not using) were admitted to the hospital, emergency room and intensive care unit less often, received medical imaging (including chest radiographs), invasive ventilation and sedatives less often, and fewer of them died in hospital. More of them received home care, noninvasive 
TABLE 3 Characteristics of COPD patients using palliative home care (PHC) in five timing categories

\begin{tabular}{|c|c|c|c|c|c|}
\hline \multirow[t]{2}{*}{ Demographics } & \multicolumn{5}{|c|}{ PHC timing before death days } \\
\hline & $>360$ & $360-181$ & $180-91$ & $90-31$ & $30-1$ \\
\hline Selected group \# & $110(6.3)$ & $129(7.4)$ & $143(8.2)$ & $262(15.0)$ & $1107(63.2)$ \\
\hline Male & $71(64.5)$ & $68(52.7)$ & $91(63.6)$ & $155(59.2)$ & $676(61.1)$ \\
\hline Female & 39 (35.5) & $61(47.3)$ & $52(36.4)$ & $107(40.8)$ & $432(39.0)$ \\
\hline $65-74$ & $17(15.5)$ & $28(21.7)$ & $26(18.2)$ & $56(21.4)$ & $153(13.8)$ \\
\hline $75-84$ & $44(40.0)$ & $40(31.0)$ & $56(39.2)$ & $108(41.2)$ & $396(35.8)$ \\
\hline $85-94$ & $33(30.0)$ & $37(28.7)$ & $38(26.6)$ & $71(27.1)$ & $450(40.7)$ \\
\hline$\geqslant 95$ & 2 (1.8) & $6(4.7)$ & $4(2.8)$ & $2(0.8)$ & $52(4.7)$ \\
\hline \multicolumn{6}{|l|}{ Educational level" } \\
\hline None & 9 (8.2) & $19(14.7)$ & $7(4.9)$ & 19 (7.3) & $100(9.0)$ \\
\hline \multicolumn{6}{|l|}{ Household type } \\
\hline Single person & 30 (27.3) & $36(27.9)$ & $34(23.8)$ & $61(23.3)$ & $250(22.6)$ \\
\hline Living together, with no children in household & $50(45.5)$ & $60(46.5)$ & 77 (53.8) & $130(49.6)$ & $496(44.8)$ \\
\hline Living together, with children in household & 9 (8.2) & $9(7.0)$ & $11(7.7)$ & $21(8.0)$ & $83(7.5)$ \\
\hline One-parent family & $7(6.4)$ & $10(7.8)$ & $8(5.6)$ & $20(7.6)$ & $62(5.6)$ \\
\hline Other household types & $2(1.8)$ & $1(0.8)$ & 1 (3) & $9(3.4)$ & $19(1.7)$ \\
\hline Collective (nursing home, psychiatric hospital) & $12(10.9)$ & $13(10.1)$ & $12(8.4)$ & $21(8.0)$ & $197(17.8)$ \\
\hline \multicolumn{6}{|l|}{ Urbanisation $\pi$} \\
\hline Very high & $32(29.1)$ & $41(31.8)$ & $38(26.6)$ & $85(32.4)$ & $294(26.6)$ \\
\hline High & 39 (35.5) & $37(28.7)$ & 39 (27.3) & $70(26.7)$ & $299(27.0)$ \\
\hline Average & $20(18.2)$ & $28(21.7)$ & $43(30.1)$ & $67(25.6)$ & 304 (27.5) \\
\hline Low & $17(15.5)$ & $21(16.3)$ & $18(12.6)$ & $37(14.1)$ & $175(15.8)$ \\
\hline Rural & $1(0.9)$ & $2(1.6)$ & $4(2.8)$ & $2(0.8)$ & $24(2.2)$ \\
\hline 0 & 91 (82.7) & $112(86.8)$ & $126(88.1)$ & $230(87.8)$ & $882(79.7)$ \\
\hline 1 & $14(12.7)$ & 10 (7.8) & $10(7.0)$ & 18 (6.9) & 159 (14.4) \\
\hline 2 & $4(3.6)$ & $5(3.9)$ & $5(3.5)$ & $12(4.6)$ & 52 (4.7) \\
\hline$\geqslant 3$ & $1(0.9)$ & $2(1.6)$ & $2(1.4)$ & $2(0.8)$ & $14(1.3)$ \\
\hline \multicolumn{6}{|l|}{ Income In, $^{-}$} \\
\hline Lowest 40\% & 9 (8.2) & 19 (14.7) & 19 (13.3) & 31 (11.8) & 107 (9.7) \\
\hline $41-60 \%$ & $62(56.4)$ & 69 (53.5) & $84(58.7)$ & $152(58.0)$ & $622(56.2)$ \\
\hline Highest 39\% & 39 (35.5) & 41 (31.8) & $40(28.0)$ & 79 (30.2) & 378 (34.1) \\
\hline
\end{tabular}

Data are presented as $\mathrm{n}(\%)$, median (interquartile range) or mean $\pm \mathrm{SD}$, unless otherwise stated. LOS: length of stay; DBD: days before death. ${ }^{\#}$ : of the total population receiving palliative home care, $n=1751$ (1.1\% of total population); ${ }^{\Uparrow}$ : Column percentages; ${ }^{+}$: income percentages represent the proportion of the total population's income.

ventilation, opioids and morphine, had GP contact, and died at home or in a nursing home. Mean total healthcare costs were $€ 1569$ lower ( $€ 5034,95 \%$ CI $€ 4703-5364$ versus $€ 6603,95 \%$ CI $€ 6546-6659)$. These results were similar for all four PHC timing categories (versus no PHC), although the differences for the majority of medical resources and costs were largest for those who used PHC 90-31 days before death.

Interpretation of the results

A first striking result was that PHC users had lower hospital-based and specialist medical resource use leading to lower inpatient costs than non-PHC users. This confirms previous research and advocates for 
TABLE 4 Medical resource use in the last 30 days before death for COPD patients lusing palliative home care (PHC))

\begin{tabular}{|c|c|c|c|}
\hline \multirow[t]{2}{*}{ Medical resource use and costs } & \multicolumn{2}{|c|}{ Bivariate results } & \multirow{2}{*}{$\begin{array}{c}\text { Multivariate results } \\
\text { PHC >30 DBD versus no PHC, } \\
\text { OR }^{\text {ๆ }}(\mathrm{Cl} 95 \%)\end{array}$} \\
\hline & No $\mathrm{PHC}^{\#}$ & $\mathrm{PHC}>30 \mathrm{DBD}^{\#}$ & \\
\hline Selected groups ${ }^{\S}$ & $56776(97.0)$ & $644(1.1)$ & \\
\hline \multicolumn{4}{|l|}{ Admissions and care interventions } \\
\hline Hospital admission & 27169 (47.9) & $159(24.7)$ & $0.35(0.32-0.40)$ \\
\hline LOS hospital admission & $5.3(5.2-5.4)$ & $2.6(2.3-2.9)$ & $0.37(0.34-0.42)$ \\
\hline ICU admission & $10884(19.2)$ & 24 (3.7) & $0.16(0.12-0.20)$ \\
\hline LOS ICU & $1.0(0.9-1.0)$ & $0.1(0.1-0.2)$ & $0.16(0.12-0.20)$ \\
\hline Palliative care unit admission & $780(1.4)$ & $49(7.6)$ & $2.61(2.01-3.39)$ \\
\hline LOS palliative care unit & $0.1(0.1-0.1)$ & $0.3(0.2-0.4)$ & $2.63(2.04-3.45)$ \\
\hline ODC admission & $1208(2.1)$ & $6(0.9)$ & not enough cases \\
\hline ER admission & $22360(39.4)$ & $126(19.6)$ & $0.43(0.38-0.48)$ \\
\hline Home care & $18294(32.2)$ & $471(73.1)$ & $3.27(2.91-3.66)$ \\
\hline GP contact & $42818(75.4)$ & $587(91.1)$ & $4.65(3.77-5.74)$ \\
\hline Number of GP contacts & $2.4(2.4-2.4)$ & $5.7(5.5-5.9)$ & $5.26(4.76-5.88)$ \\
\hline Specialist contact & 9566 (16.9) & 59 (9.2) & $0.58(0.50-0.69)$ \\
\hline Number of specialist contacts & $0.2(0.2-0.2)$ & $0.1(0.1-0.2)$ & $0.61(0.52-0.72)$ \\
\hline Physiotherapist contact & $28643(50.5)$ & $358(55.6)$ & $0.94(0.85-1.04)$ \\
\hline Number of physiotherapist contacts & $5.7(5.6-5.8)$ & $5.5(5.1-5.8)$ & $0.81(0.74-0.89)$ \\
\hline \multicolumn{4}{|l|}{ Procedures } \\
\hline Invasive ventilation & $4864(8.6)$ & $8(1.2)$ & $0.13(0.08-0.21)$ \\
\hline Noninvasive ventilation & $13795(24.0)$ & $394(61.2)$ & $2.65(2.39-2.93)$ \\
\hline Gastric tube & $116(0.2)$ & $3(0.5)$ & $2.15(1.11-4.16)$ \\
\hline Urinary tract catheter & $202(0.4)$ & $3(0.5)$ & $1.02(0.44-2.34)$ \\
\hline CPR & $1031(2.0)$ & $2(0.3)$ & $0.09(0.02-0.36)$ \\
\hline Medical imaging & $34010(60.0)$ & $174(27.0)$ & $0.34(0.31-0.38)$ \\
\hline Chest radiograph & $31757(56.0)$ & $162(25.2)$ & $0.34(0.31-0.38)$ \\
\hline Number of chest radiographs & $2.6(2.5-2.6)$ & $0.7(0.6-0.8)$ & $0.34(0.31-0.38)$ \\
\hline Spirometry & $66(0.1)$ & $0(0.0)$ & Not enough cases \\
\hline \multicolumn{4}{|l|}{ Medication } \\
\hline Oxygen & $3473(6.1)$ & $90(14.0)$ & $2.22(1.89-2.61)$ \\
\hline Opioids & $18775(33.1)$ & $430(66.8)$ & $4.04(3.63-4.49)$ \\
\hline Sedatives & $11357(20.0)$ & $81(12.6)$ & $0.48(0.41-0.57)$ \\
\hline Morphine & 7465 (13.2) & $279(43.3)$ & $5.29(4.78-5.86)$ \\
\hline COPD drugs & $35319(62.2)$ & $411(63.8)$ & $0.97(0.87-1.07)$ \\
\hline \multicolumn{4}{|l|}{ Place of death ${ }^{+}$} \\
\hline Hospital death & $31225(55.0)$ & $274(15.6)$ & $0.14(0.13-0.16)$ \\
\hline Home death & $14731(25.9)$ & 1064 (60.8) & $4.77(4.29-5.30)$ \\
\hline Death in nursing home or residence & $10820(19.1)$ & $413(23.6)$ & $1.72(1.50-1.96)$ \\
\hline
\end{tabular}

Data are presented as $\mathrm{n}(\%)$ or mean $(95 \% \mathrm{Cl})$, unless otherwise stated. DBD: days before death; LOS: length of stay (in days); ICU: intensive care unit; ODC: one day care; ER: emergency room; GP: general practitioner; CPR: cardiopulmonary resuscitation. \#: column percentages; ๆ: odds ratios with reference category: no PHC, controlled for age, household type, attained educational level, urbanisation, year of death, amount of comorbidity, amount of home care visits with a palliative character from a community nurse in the last 360 days before death and care intensity parameters in the last 365 days before death (Appendix 1); ${ }^{+}$: for place of death, those who received PHC $\leqslant 30$ DBD were also included, hence $n=1751$; $\S$ : percentage of total population included in the database $(n=58527)$.

better implementation of PHC in COPD. For example, hospitalisation occurred less often, similar to a 2016 hospital-based palliative care programme for COPD [8]. Dying at home also happened more (odds ratio 4.77), higher than the 2.21 odds ratio in a Cochrane review of 23 PHC trials for advanced illness (including COPD) but similar to a Belgian population study of chronically ill (including COPD) [13]. GP contact was high for both PHC users and non-users (91.1\% and $75.4 \%)$, but differed in the frequency of contact (mean 5.7 versus 2.4). In comparison, MAETENs et al. [13] reported 3.1 versus 0.8 mean GP frequency in the final 14 days before death for chronically ill people.

Our results can also be related to a previous study that developed and validated quality indicators [26], i.e. "well-defined and measurable aspects of care" [27] to measure appropriate and inappropriate end-of-life care in COPD. This reveals that using PHC increases appropriate healthcare resources, such as GP contact, 

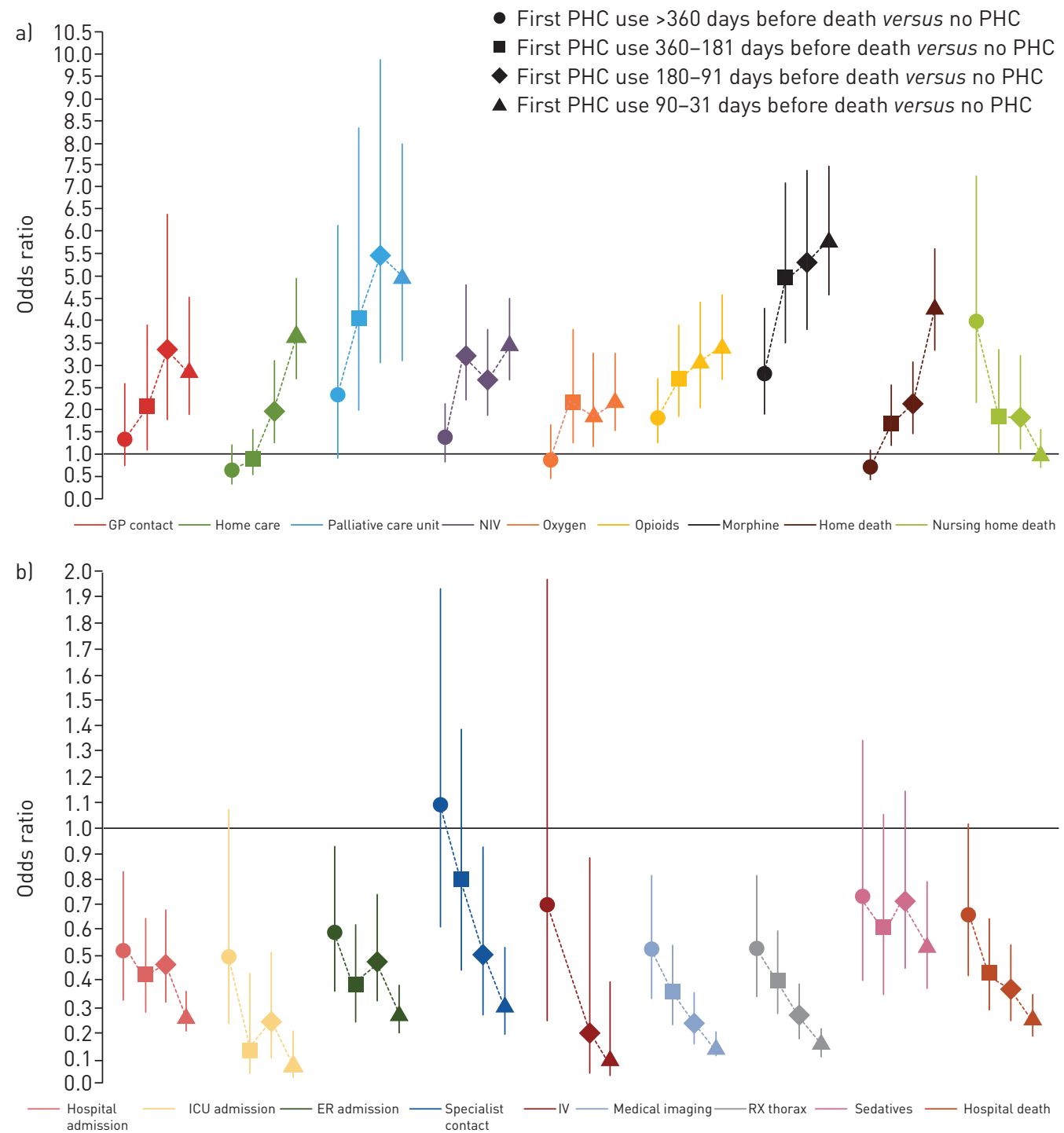

FIGURE 2 Medical resource use in the last 30 days before death for COPD patients lusing palliative home care (PHC) >360, 360-181, 180-91 and 90-31 days before death). GP: general practitioner; NIV: noninvasive ventilation; ICU: intensive care unit; ER: emergency room; IV: invasive ventilation; RX: radiograph.

opioids, oxygen, home death or nursing home death [26]. This also somewhat confirms the GOLD guidelines which state that in the final stages of life, opioids may relieve breathlessness and oxygen may offer some benefit even if the patient is not hypoxaemic [28]. Likewise, we found indications of PHC decreasing inappropriate resource use, such as excessive admissions and medical imaging.

We observed very low (3.0\%) and late PHC use $(63.2 \%$ in last 30 days before death, with a median of four days) in all 58527 COPD deaths. This is significantly lower than the $7.2 \%$ in a 2013 Flemish [3] and $13.5 \%$ in a Belgian study [13]. However, the latter included cancer patients, which probably explains the higher referral rate [29]. Frequently mentioned reasons for low and late referral in COPD are the unpredictable COPD trajectory and lower disease insight amongst patients in terms of severity, survival but also on the benefits of PHC [30]. Some health professionals believe PHC is not meaningful or too time-consuming in COPD [3]. Despite low and late PHC use, its association with more appropriate (in terms of disease stage) end-of-life care shows that health policy should take PHC better into account when designing care plans for COPD. Policy measures could try increasing PHC access by incorporating PHC knowledge and skills more effectively into educational programmes [31] and by creating public awareness campaigns about PHC and COPD [32].

The results on timing further revealed that all timing categories positively affect patient-centred medical resource use and lower inpatient and total costs in the last 30 days before death compared to no PHC. 
TABLE 5 Healthcare costs in the last 30 days before death for COPD patients (using palliative home care (PHC))

\begin{tabular}{|c|c|c|c|c|c|c|c|c|c|c|c|c|}
\hline \multirow[t]{3}{*}{ Healthcare costs $€$} & \multicolumn{4}{|c|}{ PHC use versus no PHC use } & \multicolumn{8}{|c|}{ Timing of receiving PHC for the first time in days before death } \\
\hline & \multicolumn{2}{|c|}{ No PHC $(n=56776)$} & \multicolumn{2}{|c|}{$P H C>30$ DBD $(n=644)$} & \multicolumn{2}{|c|}{$>360(n=110)$} & \multicolumn{2}{|c|}{$360-181(n=129)$} & \multicolumn{2}{|c|}{$180-91(n=143)$} & \multicolumn{2}{|c|}{$90-31(n=262)$} \\
\hline & $\begin{array}{c}\text { Mean } \\
(95 \% \mathrm{Cl})\end{array}$ & Median (IQR) & $\begin{array}{c}\text { Mean } \\
(95 \% \mathrm{Cl})\end{array}$ & Median (IQR) & $\begin{array}{c}\text { Mean } \\
(95 \% \mathrm{Cl})\end{array}$ & Median (IQR) & $\begin{array}{c}\text { Mean } \\
(95 \% \mathrm{Cl})\end{array}$ & Median (IQR) & $\begin{array}{c}\text { Mean } \\
(95 \% \mathrm{Cl})\end{array}$ & Median (IQR) & $\begin{array}{c}\text { Mean } \\
(95 \% \mathrm{Cl})\end{array}$ & Median (IQR) \\
\hline \multirow{6}{*}{$\begin{array}{l}\text { Total inpatient } \\
\text { costs } \\
\text { Total outpatient } \\
\text { costs } \\
\text { Total costs }\end{array}$} & 5583 & 2897 & 2492 & 0 & 2762 & 0 & 2529 & 0 & 3043 & 0 & 2059 & 0 \\
\hline & $(5526-5641)$ & $(0-9316)$ & (2142-2841) & $(0-3224)$ & (1912-3611) & (0-4822) & (1742-3316) & $(0-2560)$ & (2185-3902) & (0-4455) & $(1562-2556)$ & (0-2185) \\
\hline & 1020 & 734 & 2542 & 2544 & 2286 & 2250 & 2347 & 2493 & 2421 & 2311 & 2811 & 2862 \\
\hline & $(1010-1029)$ & (355-1365) & $(2422-2661)$ & $(1414-3380)$ & $(1990-2582)$ & $(1079-3181)$ & (2115-2579) & $(1316-3180)$ & (2179-2664) & (1471-3370) & (2612-3010) & $(1641-3626)$ \\
\hline & 6603 & 4265 & 5034 & 3555 & 5048 & 3237 & 4876 & 3489 & 5465 & 3453 & 4870 & 3633 \\
\hline & $(6546-6659)$ & (1248-10335) & $(4703-5364)$ & $(2497-6243)$ & $(4246-5850)$ & (2239-7215) & $(4160-5593)$ & (2169-5971) & $(4618-6312)$ & (2157-7252) & (4404-5335) & (2776-5780) \\
\hline
\end{tabular}


This aligns with patients' preferences to start palliative care earlier, according to a recent US-based study [33]. Still, of all timing categories, using PHC for the first time 90-31 days before death differed the most from not using PHC in terms of fewer hospital admissions, less medical imaging including chest radiographs, more prescriptions for opioids and morphine and more contact with GPs. This surprisingly late timing for the best effect does contrast somewhat with the large body of intervention studies [16, 34-37] and recommendations $[6,31,38,39]$ for early integration of palliative care (albeit mostly in cancer populations). We see three possible explanations.

Firstly, late (90-31 days before death) PHC users may have been in worse health than early (>360 days before death) users. This could explain the formers' higher patient-centred and comfort care to prepare for impending death. We controlled for worse health by measuring care intensity, such as hospital and intensive care unit admissions in the two years leading to death. Research in fact considers hospitalisation for an acute exacerbation a good predictor of poor health or even impending death in COPD [40]. Still, we could not measure all illness-related aspects of worse health that may influence resource use. For example, earlier PHC use may indicate higher uncertainty about prognosis, which may lead to different care choices in the last 30 days before death.

Second, our analysis did not account for possible differences in PHC intensity. As the data only allowed measuring first referral to PHC, earlier PHC users might have received fewer PHC visits or may even stopped PHC visits altogether before the final 30 days before death [38]. These patients could have returned to merely life-prolonging care. Finally, care preferences of health professionals or their views on the meaningfulness of PHC [3] and preferences of patients and family members [30] were impossible to assess but could have differed between PHC timing categories. Further research should take those in account for better analysis of medical resource use and costs. Despite these findings, our study still shows that, regardless of PHC timing, it affects medical resource use and costs in the same direction.

\section{Strengths and limitations}

This was, to our knowledge, the first retrospective population study of PHC use and timing on medical resource use and costs in the last 30 days before death for COPD. We were able to use full population data from Belgians who died between 2010 and 2015. Linking seven databases enabled medical resource use and cost analysis while considering socio-demographical confounders, leading to a large quantity of results on care interventions, admissions, procedures and medication use. Health policies designs can use this information concerning access or lack of access to PHC in the COPD population.

We acknowledge several limitations of our study. Firstly, because of the retrospective design, we may assume that all medical resources and costs happened for patients who were in the final stage of illness, while this might not be completely true [41]. Next, using administrative databases does not allow examination of specific patient, informal caregiver or health professional preferences that might have influenced medical decisions and patterns of medical service use.

Moreover, the severity of the disease or the number of exacerbations might also influence decisions on end-of-life resource use in the last 30 days before death for COPD. However, due to a lack of specific diagnostic information available on medical files, we could not account for such confounders. Nevertheless, a retrospective design did allow us to measure real-life performance in end-of-life care for COPD patients [42]. We also simulated the conditions (controlling for confounders, exposure to PHC before receiving medical resource use) for a randomised controlled trial in the best possible way.

A third limitation was the lack of data on services not covered by insurers, such as mobile hospital palliative care teams [18]. It was also impossible to gather information on PHC intensity (frequency of visits) because the data only provided information about the first $\mathrm{PHC}$ visit. We tried to solve this by controlling for the number of community nurse visits with a palliative nature, which could be an indicator for the frequency of PHC visits. Lastly, to identify those who died with COPD, we used a validated algorithm as well as the intermediate and associated causes of death indicated on the death certificates. However, by using the algorithm, it was impossible to determine the specific level of the disease from our data, since only dispensing data and not prescription data were available. Although there is no standard validated algorithm, the use of pharmacy data to identify COPD patients in administrative databases was found adequate in previous studies [43].

\section{Conclusion}

PHC use is strongly associated with increased appropriate patient-centred medical resource use and lower inpatient and total costs in the last 30 days before death for COPD compared to no PHC. Patients received more home care, noninvasive ventilation, opioids and morphine more often, had more contact with their GP and more of them died at home or in a nursing home. PHC given any time between 720 and 30 days 
before death gave similar results. However, the largest differences were for the majority of medical resources and costs seen in using PHC 90-31 days before death. The results suggest that health policy and services should focus on increasing PHC access for COPD, while research should further explore the timing effects of early PHC for COPD.

Acknowledgements: The authors wish to thank Birgit Gielen (IMA), Liesbet Van Eycken (BCR), and Patrick Lusyne (Statistics Belgium) for helpful assistance and preparation of the databases and article. The authors would also like to thank Helen White for her language editing and Arno Maetens and Robrecht De Schreye for their contributions to the data analysis.

Author contributions: Concept and idea of the study: C. Scheerens, K. Faes, K. Chambaere and J. Cohen. Data collection: K. Faes and J. Cohen. Data analysis: K. Faes, C. Scheerens and K. Chambaere. Data interpretation: K. Faes, C. Scheerens, K. Beernaert, K. Chambaere, L. Deliens, J. Cohen, P. Pype, G. Joos and E. Derom. Leading the writing of the paper: C. Scheerens and K. Chambaere. Critical revision: C. Scheerens, K. Beernaert, K. Chambaere, J. Cohen, L. Deliens, P. Pype, K. Faes, E. Derom and G. Joos. Read the final version: C. Scheerens, K. Beernaert, K. Chambaere, J. Cohen, P. Pype, L. Deliens, K. Faes, E. Derom and G. Joos.

Support statement: SBO IWT (number 140009) and Het Fonds Wetenschappelijk Onderzoek (FWO, Research Foundation-Flanders) (grant number G012414N) supported the funding of this study. K. Beernaert is a postdoctoral research fellow at FWO. Funding information for this article has been deposited with the Crossref Funder Registry.

Conflict of interest: None declared.

\section{References}

1 Soriano JB, Abajobir AA, Abate $\mathrm{KH}$, et al. Global, regional, and national deaths, prevalence, disability-adjusted life years, and years lived with disability for chronic obstructive pulmonary disease and asthma, 1990-2015: a systematic analysis for the Global Burden of Disease Study 2015. Lancet Respir Med 2017; 5: 691-706.

2 De Schreye R, Smets T, Deliens L, et al. Appropriateness of end-of-life care in people dying from COPD. Applying quality indicators on linked administrative databases. J Pain Symptom Manage 2018; 56: 541-550.

3 Scheerens C, Beernaert K, Pype P, et al. Comparing the use and timing of palliative care services in COPD and lung cancer: a population-based survey. Eur Respir J 2018; 51: 1702405.

4 Bereza BG, Troelsgaard Nielsen A, Valgardsson S, et al. Patient preferences in severe COPD and asthma: a comprehensive literature review. Int J Chron Obstruct Pulmon Dis 2015; 10: 739-744.

5 Gore JM, Brophy CJ, Greenstone MA. How well do we care for patients with end stage chronic obstructive pulmonary disease (COPD)? A comparison of palliative care and quality of life in COPD and lung cancer. Thorax 2000; 55: 1000-1006.

6 World Health Organization. WHO Definition of Palliative Care. 2000. www.who.int/cancer/palliative/definition/en/ Date last accessed: 30 March 2017.

7 Sepúlveda C, Marlin A, Yoshida T, et al. Palliative Care: the World Health Organization's global perspective. J Pain Symptom Manage 2002; 24: 91-96.

8 Cassel J B, Kerr KM, McClish DK, et al. Effect of a Home-Based Palliative Care Program on Healthcare Use and Costs. J Am Geriatr Soc 2016; 64: 2288-2295.

9 Cohen J, Beernaert K, Van den Block L, et al. Differences in place of death between lung cancer and COPD patients: a 14-country study using death certificate data. NPJ Prim Care Respir Med 2017; 27: 14.

10 Gomes B, Calanzani N, Gysels M, et al. Heterogeneity and changes in preferences for dying at home: a systematic review. BMC Palliat Care 2013; 12: 7 .

11 Gomes B, Calanzani N, Higginson IJ. Benefits and Costs of Home Palliative Care Compared With Usual Care for Patients With Advanced Illness and Their Family Caregivers. JAMA 2014; 311: 1060-1061,

12 Singer AE, Goebel JR, Kim YS, et al. Populations and Interventions for Palliative and End-of-Life Care: A Systematic Review. J Palliat Med 2016; 19: 995-1008.

13 Maetens A, Beernaert K, De Schreye R, et al. Impact of palliative home care support on the quality and costs of care at the end of life: a population-level matched cohort study. BMJ Open 2019; 9: e025180.

14 Gomes B, Calanzani N, Curiale V, et al. Effectiveness and cost-effectiveness of home palliative care services for adults with advanced illness and their caregivers. Cochrane Database Syst Rev 2013; 6: CD007760.

15 Au DH, Udris EM, Fihn SD, et al. Differences in Healthcare Utilization at the End of Life Among Patients With Chronic Obstructive Pulmonary Disease and Patients With Lung Cancer. Arch Intern Med 2006; 166: 326-331.

16 Maddocks M, Lovell N, Booth S, et al. Palliative care and management of troublesome symptoms for people with chronic obstructive pulmonary disease. Lancet 2017; 390: 988-1002.

17 Maetens A, Beernaert K, Deliens L, et al. Policy Measures to Support Palliative Care at Home: A Cross-Country Case Comparison in Three European Countries. J Pain Symptom Manage 2017; 54: 523-529.e5.

18 Maetens A, De Schreye R, Faes K, et al. Using linked administrative and disease-specific databases to study end-of-life care on a population level. BMC Palliat Care 2016; 15: 86.

19 World Health Organization. International Classification of Diseases. https://www.who.int/classifications/icd/en/

20 Zaken FB. Algemene Directie Instelling en Bevolking. Rijksregister - Rijksregister - IBZ Instellingen en Bevolking. www.ibz.rrn.fgov.be/nl/rijksregister/ Date last accessed: 25 April 2018.

21 Statistiek België. Statistics \& Analyses Census 2001 and 2011. https://statbel.fgov.be/nl. Date last accessed: 25 April 2018.

22 Faes K, Cohen J, Annemans L. Resource use during the last 6 months of life among COPD patients: a population level study. J Pain Symptom Manage 2018; 56: 318-326.

23 McGarvey LP, John M, Anderson JA, et al. TORCH Clinical Endpoint Committee. Ascertainment of cause-specific mortality in COPD: operations of the TORCH Clinical Endpoint Committee. Thorax 2007; 62: 411-415. 
24 Faes K, De Frène V, Cohen J, et al. Resource Use and Healthcare Costs of COPD Patients at the End of Life: A Systematic Review. J Pain Symptom Manage 2016; 52: 588-599.

25 Spilsbury K, Rosenwax L, Arendts G, et al. The Association of Community-Based Palliative Care With Reduced Emergency Department Visits in the Last Year of Life Varies by Patient Factors. Ann Emerg Med 2017; 69: 416-425.

26 De Schreye R, Houttekier D, Deliens L, et al. Developing indicators of appropriate and inappropriate end-of-life care in people with Alzheimer's disease, cancer or chronic obstructive pulmonary disease for population-level administrative databases: A RAND/UCLA appropriateness study. Palliat Med 2017; 31: 932-945.

27 Grunfeld E, Urquhart R, Mykhalovskiy E, et al. Toward population-based indicators of quality end-of-life care: testing stakeholder agreement. Cancer 2008; 112: 2301-2308.

28 Global Initiative for Chronic Obstructive Lung Disease. 2019. www.goldcopd.org Date last accessed: 4 December 2018.

29 Beernaert K, Cohen J, Deliens L, et al. Referral to palliative care in COPD and other chronic diseases: A population-based study. Respir Med 2013; 107: 1731-1739.

30 Scheerens C, Deliens L, Van Belle S, et al. "A palliative end-stage COPD patient does not exist": a qualitative study of barriers to and facilitators for early integration of palliative home care for end-stage COPD. NPJ Prim Care Respir Med 2018; 28: 23.

31 Kaasa S, Loge JH, Lundeby T, et al. Lancet Oncology Commission Integration of oncology and palliative care: a Lancet Oncology Commission. Lancet Oncol 2018; 19: 30486-30494.

32 World Health Organization. Strengthening Palliative Care as a Component of Comprehensive Care Throughout the Life Course https://apps.who.int/iris/handle/10665/162863

33 Iyer AS, Dionne-Odom JN, Ford SM, et al. A Formative Evaluation of Patient and Family Caregiver Perspectives on Early Palliative Care in COPD across Disease Severity. Ann Am Thorac Soc 2019; 16: 1024-1033.

34 Higginson IJ, Bausewein C, Reilly CC, et al. An integrated palliative and respiratory care service for patients with advanced disease and refractory breathlessness: a randomised controlled trial. Lancet Respir Med 2014; 2: 979-987.

35 Weber C, Stirnemann J, Herrmann FR, et al. Can early introduction of specialized palliative care limit intensive care, emergency and hospital admissions in patients with severe and very severe COPD? a randomized study. BMC Palliat Care 2014; 13: 1-7.

36 Buckingham S, Kendall M, Ferguson S, et al. HELPing older people with very severe chronic obstructive pulmonary disease (HELP-COPD): mixed-method feasibility pilot randomised controlled trial of a novel intervention. NPJ Prim care Respir Med 2015; 25: 15020.

37 Temel JS, Greer JA, El-Jawahri A, et al. Effects of Early Integrated Palliative Care in Patients With Lung and GI Cancer: A Randomized Clinical Trial. J Clin Oncol 2017; 35: 834-841.

38 Global initiative for chronic obstructive lung disease global strategy for the diagnosis, management, and prevention of chronic obstructive pulmonary disease. 2018. www.goldcopd.org Date last accessed: 29 August 2018.

39 Celli BR, MacNee W, ATS/ERS Task Force. Standards for the diagnosis and treatment of patients with COPD: a summary of the ATS/ERS position paper. Eur Respir J 2004; 23: 932-946.

40 Piquet J, Chavaillon J-M, David P, et al. High-risk patients following hospitalisation for an acute exacerbation of COPD. Eur Respir J 2013; 42: 946-955.

41 Scitovsky AA. "The high cost of dying": what do the data show? 1984. Milbank Q 2005; 83: 825-841.

42 Hollingworth W, Biswas M, Maishman RL, et al. The healthcare costs of heart failure during the last five years of life: A retrospective cohort study. Int J Cardiol 2016; 224: 132-138.

43 Smidth M, Sokolowski I, Kærsvang L, et al. Developing an algorithm to identify people with Chronic Obstructive Pulmonary Disease (COPD) using administrative data. BMC Med Inform Decis Mak. 2012; 12: 38. 